\title{
The association of depressive symptoms in patients with acute myocardial infarction in a regional hospital in Durban, South Africa
}

Chiara Sookan", Naresh Ranjith", Ben Sartorius ${ }^{\dagger}$ and Suvira Ramlall ${ }^{\triangleright}$

*Department of Psychiatry, Nelson R. Mandela School of Medicine, University of KwaZulu-Natal, Durban, South Africa

\#Department of Medicine, Nelson R. Mandela School of Medicine, University of KwaZulu-Natal; City Hospital (JMH), Durban, South Africa

tDepartment of Public Health Medicine, School of Nursing and Public Health, University of KwaZulu-Natal, Durban, South Africa 'Discipline of Psychiatry, Nelson R. Mandela School of Medicine, University of KwaZulu-Natal, King Dinuzulu Hospital Complex, Durban, South Africa

Address for correspondence:

Prof N. Ranjith

Cardiovascular Research Centre

70 Krishna Rabilal Road

Merebank

Durban

4052

South Africa

Email:

ranjith@lantic.co.za

\section{INTRODUCTION}

Although depression develops in almost $20 \%$ of patients after myocardial infarction (MI) and is suspected as a risk factor for $M I,(1)$ the mechanisms linking depression and $\mathrm{Ml}$ still remain unclear. ${ }^{(2)}$ Recent observations suggest that the relationship between depression and $\mathrm{Ml}$ is both complex and bi-directional. ${ }^{(2,3)}$ Depression is suspected as a risk factor for $\mathrm{MI}$ whilst $\mathrm{MI}$ can contribute to depression, both in acute disease onset and prognosis after a MI. ${ }^{(1,4)}$

Data from several studies have described one, or more, possible triggers for $\mathrm{Ml}$, the most common of which is emotional distress. ${ }^{(5,6)}$ The INTERHEART study, a world-wide study of cardiac risk factors in patients with $\mathrm{MI}$, found that stressful life events occurred more frequently within the prior year among patients with MI. (7) These factors included: marital separation or divorce, loss of job, loss of crop or business failure, retirement, violence, major intra-family conflict, death of a family member and major personal injury. An increase in cardiovascular events has also been associated with natural disasters. ${ }^{(8,9)}$

\section{ABSTRACT}

Objective: To examine the association of depressive symptoms and contributing psychosocial factors during hospitalisation and I-month post discharge in patients with acute myocardial infarction (MI).

Methods and results: The study population comprised consecutive patients from a multi-ethnic background, admitted June 2015 - November 2015 to the Coronary Care Unit at R. K. Khan Hospital, Durban, South Africa, with a diagnosis of MI. Demographic and clinical data stored in a specialised electronic cardiac database were extracted for all patients. Patients were screened for depressive symptoms using the Cardiac Depression Scale (CDS). Levels of perceived stress were evaluated using the 4-item Perceived Stress Scale (4-PSS).

The study cohort consisted of 117 patients with a mean age of $58.16 \pm 11.12$ years, the majority of whom were males $(70 \%$, mean age $56.54 \pm 1.23$ years) and $30 \%$ females (mean age $61.97 \pm 1.75$ years). Forty-nine percent of the participants were diagnosed with depressive symptoms with a significantly greater number of females experiencing depressive symptoms compared to males $(p<0.01)$. Patients with depressive symptoms were more likely to have a previous history of depression $(p=0.02)$, positive family history of depression $(p=0.04)$, greater non-adherence to their medication $(p<0.01)$ and lower levels of physical activity $(p<0.01)$. Depressed patients also reported higher levels of stress on voluntary $(p<0.0 I)$ and subjective rating $(p<0.0 I)$, experienced greater financial stress $(p<0.01)$, major life events $(p<0.01)$ and had higher 4-PSS scores $(p<0.01)$. Thirteen percent of patients experienced major adverse cardiac events (MACE) with a significantly greater number of events found in those with depressive symptoms $(p<0.01)$.

Conclusion: Depressive symptoms are a common finding in a South African population presenting with MI. They are linked to higher rates of MACE, a previous history and/or family history of depression, greater stress levels and major life events. Females with MI are significantly more likely to present with depressive symptoms. These findings suggest that patients with MI should be screened for depressive symptoms and psychosocial factors as this may serve as an important arena for research and therapeutic intervention. SAHeart 2018;15:108-115 
Even though there is an increasing body of evidence supporting a relationship between depressive symptoms and $\mathrm{MI}$, such information is scarce or non-existent in South Africa. A local study that examined the association between traditional risk factors and acute $\mathrm{MI}$ in 4418 patients, listed the absence of psychosocial data as one of the limitations in their analysis. ${ }^{(10)}$ Therefore, the present study examines the association of depressive symptoms and contributing psychosocial factors with $\mathrm{MI}$ in a South African setting during hospitalisation and I-month post discharge.

\section{METHODOLOGY}

This prospective study was conducted at R. K. Khan Hospital, a large referral hospital in Durban, KwaZulu-Natal, South Africa. The hospital services a large geographical area, including the township of Chatsworth, which is historically home to a predominantly Asian Indian population. All English speaking patients who were admitted to the hospital's Coronary Care Unit (CCU) from June 2015 - November 20I5, with a confirmed diagnosis of acute $\mathrm{Ml}$ as defined by the Joint European Society of Cardiology/American College of Cardiology Committee ${ }^{(I I)}$ were included in the study. Ethical approval was obtained from the Biomedical Research Ethics Committee (BREC) of the University of KwaZulu-Natal. Participation was voluntary and written informed consent was obtained from all patients prior to any study related procedures. Patients were excluded if they suffered from cognitive impairment, including delirium or intellectual disability, malignancies, chronic renal failure, hypothyroidism, or other life-threatening diseases.

Relevent clinical information, laboratory results and sociodemographic data stored in an electronic database were extracted for all eligible patients. The following cardiovascular risk factors were assessed: self-reported diagnosis of hypertension, diabetes mellitus, history of smoking (never, previous, or current), visceral obesity based on ethnic specific waist circumference cut-offs, and a family history of vascular disorders. Additional clinical data included a detailed description of major adverse cardiac events (MACE) encountered during hospital admission and at I-month follow-up such as arrhythmias, heart failure, cardiogenic shock, death, complete heart block and recurrence of angina and $\mathrm{Ml}$.

\section{THE CARDIAC DEPRESSION SCALE}

Patients were screened for depressive symptoms 48 hours after admission to hospital and at 30-days post discharge to exclude an adjustment reaction to the $\mathrm{MI}$ or the hospitalisaion. The Cardiac Depression Scale (CDS), a 26-item self-report instrument, was used to screen for depressive symptoms. ${ }^{(12)}$
It is the only validated instrument designed to measure depression in cardiac patients and is capable of detecting symptoms ranging from subclinical to severe depression. It has been established to be a reliable and sensitive measure in English speaking populations. ${ }^{(13,14)}$ The scale is made up of 2 dimensions and 7 subscales including: sleep, anhedonia, uncertainty, mood, cognition, hopelessness and inactivity. Each item is scored using a Likert-scale of I (strongly disagree) to 7 (strongly agree). A higher score is indicative of more severe depression (range 26 - 182). Depressive scores were evaluated as 3 categorical variables: $<80$ was defined as not depressed, $\geq 80$ but $<100$ was defined as minor depressive symptoms and $\geq 100$ as major depressive symptoms. ${ }^{(13,14)}$ Using these cut-off scores, the CDS has been shown to have a sensitivity of $95 \%$ and a specificity of $92 \%$ for major depressive symptoms and a sensitivity of $94 \%$ and specificity of $77 \%$ for minor depressive symptoms in cardiac inpatients and outpatients. ${ }^{(14)}$

\section{PERCEIVED STRESS SCALE}

The participants' level of perceived stress was evaluated using the 4-Item Perceived Stress Scale (4-PSS), which is a valid and reliable instrument that measures psychological distress. ${ }^{(15)}$ The 4 questions ask respondents how often they felt unable to control their lives, handle their difficulties, felt things were going their way and could not overcome their difficulties. Total PSS scores ranged from 0 - 16 with higher scores indicating more perceived stress.

Furthermore, each participant completed a questionnaire that elicited information regarding their family and psychiatric history as well as lifestyle factors including level of physical activity, alcohol use, pscyho-social stressors and adherance to their chronic medication.

\section{STATISTICAL ANALYSES}

Data was processed and analysed using Stata 13.0. (StataCorp. 2013 Statiscal Software Release 13, College Station, TX: StataCorp LP). Categorical factors associated with depression were assessed using the standard Pearson's chi-square $(\chi 2)$ test. If an expected cell count in the cross tabulation was less than 5 (sparse numbers) then the Fisher's exact test was preferred. Comparison of predictors by binary depressed classification was assessed using the standard t-test. If the normality assumption was not upheld, then the non-parametric equivalent Wilcoxon rank-sum test was used instead. Strength of association between explanatory factors and depressed status was assessed using a bivariate logistic regression. Coefficients were exponentiated to present odds ratios (ORs). A p-value of $<0.05$ was considered statisically significant. 


\section{RESULTS}

One hundred and twenty nine patients were admitted with $\mathrm{MI}$ over the study period. Twelve patients in total were excluded from the study, 5 of whom because they were unable to complete their questionnaire due to language difficulities and the other 7 due to the study's exclusion criteria. The final study sample consisted of I 17 patients with acute $\mathrm{MI}$, with a mean age of $58.16 \pm 11.12$ years, the majority of whom were males ( $n=82$ [70\%]) as per Table I. Female patients were older than their male counterparts (mean age 61.97 \pm 1.75 vs. 56.54 \pm 1.23 years, respectively).

Eighty-eight percent of the patients were of Asian Indian origin, 8.6\% were White, 2.6\% Black African and 0.9\% Coloured. Visceral obesity (71\%), dyslipidaemia (71\%), diabetes mellitus (59\%) and hypertension (59\%) were the most commonly observed risk factors among study subjects. The principal source of income for $51 \%$ of patients was from pension funds, while the majority (74\%) had completed their secondary level of education and 13\% obtained a tertiary level education. Sixtyfour percent $(n=75)$ experienced a major life event in the year prior to their admission to CCU.

Demographic and clinical characteristics of patients with (49\%) and without (51\%) depressive symptoms are presented in Table II. A significantly greater number of females experienced in-hospital depressive symptoms compared to males (OR 3.24 $[95 \% \mathrm{Cl}$ I.4 - 7.5]; $\mathrm{p}<0.01$ ). Patients who suffered from depressive symptoms during hospitalisation were more likely to have a previous history of depression (OR 8.07 [95\% Cl I.19 - 54.95]; $p=0.02)$, a positive family history of depression (OR 4.04 [95\% Cl I.05 - 15.54]; $p=0.04$ ), a greater nonadherence to their medication (OR 1.53 [95\% Cl I.07 - 2.19]; $\mathrm{p}<0.0 \mathrm{I}$ ) and lower levels of physical activity (OR 2.39 [95\% Cl I.I4 - 5.0I]; $p<0.01$ ). These patients also reported higher levels of stress on voluntary (OR $7.9[95 \% \mathrm{Cl} 3.45$ - 18.1]; $\mathrm{p}<0.0 \mathrm{I}$ ) and subjective rating (OR 5.63 [95\% Cl 2.63 - 12.02]; $p<0.01$ ), experienced greater financial stress (OR $2.64[95 \%$ $\mathrm{Cl}$ I.44 - 4.84]; $p<0.0 \mathrm{I}$ ), and major life events (OR 4.47 [95\% Cl I.95 - 10.25]; $p<0.01$ ) and had higher 4-PSS scores (medium vs. low OR 24.73 [95\% Cl 8.14 - 75.I2], high vs. low OR 100.7 [95\% Cl I $2.07-840.1] ; p<0.0$ I).

Fifteen patients (13\%) experienced MACE, with a greater number of events occuring in those with depressive symptoms (23\%) compared to those without (3\%) (OR 8.57 [95\% Cl 1.84 - 39.94]; $p<0.01$ ). The 15 index events were: 8 heart failures, 2 ventricular arrymthias, I cardiogenic shock, 2 atrial fibrillation and 2 deaths (both the deceased patients had depressive symptoms).
TABLE I: Baseline demographic and clinical

characteristics.

\begin{tabular}{|c|c|}
\hline Characteristics & Summary $(n=117)(\%)$ \\
\hline Age (years), mean (SD) & $58.16 \pm 11.12$ \\
\hline Male (mean age $56.54 \pm 1.23$ years) & $82(70)$ \\
\hline Female (mean age $61.97 \pm 1.75$ years) & $35(30)$ \\
\hline \multicolumn{2}{|l|}{ Race } \\
\hline Asian Indian & $103(88)$ \\
\hline White & $10(8.6)$ \\
\hline Black & $3(2.6)$ \\
\hline Coloured & I (0.9) \\
\hline STEMI* & $74(63)$ \\
\hline NSTEMI** & $43(37)$ \\
\hline \multicolumn{2}{|l|}{ Risk Factors } \\
\hline Visceral obesity & $83(7 \mid)$ \\
\hline Dyslipidaemia & $83(7 \mathrm{I})$ \\
\hline Diabetes Mellitus & $69(59)$ \\
\hline Hypertension & $69(59)$ \\
\hline Previous Ml & $28(24)$ \\
\hline MACE*** & $15[13]$ \\
\hline \multicolumn{2}{|l|}{ Behavioural factors } \\
\hline Smoking & $82(72)$ \\
\hline Adherent to chronic medication & $63(54)$ \\
\hline Physical activity & $58(50)$ \\
\hline Alcohol use & $47(40)$ \\
\hline \multicolumn{2}{|l|}{ Marital Status } \\
\hline Married/co-habiting & $85(73)$ \\
\hline Widowed & $19(16)$ \\
\hline Divorced/separated & $9(8)$ \\
\hline Single & $4(3)$ \\
\hline \multicolumn{2}{|l|}{ Educational Level } \\
\hline Secondary & $87(74)$ \\
\hline Primary & $15(13)$ \\
\hline Tertiary & $15(13)$ \\
\hline \multicolumn{2}{|l|}{ Source of Income } \\
\hline Pension & $60(51)$ \\
\hline Employed & $40(34)$ \\
\hline Other & $17(15)$ \\
\hline \multicolumn{2}{|l|}{ Psychiatric factors } \\
\hline Current history of depression & $6(5)$ \\
\hline Past history of depression & $5(4)$ \\
\hline Family history of depression & $13(11)$ \\
\hline \multicolumn{2}{|l|}{ Subjective stress rating at home/work } \\
\hline Never & $6(5)$ \\
\hline Sometimes & $69(59)$ \\
\hline Several periods & $33(28)$ \\
\hline Permanent & $9(8)$ \\
\hline Major life events in last I year & $75(64)$ \\
\hline Death of family member & $21(18)$ \\
\hline Other major stress & $20(17)$ \\
\hline Intra-family conflict & II (9) \\
\hline Job loss & $10(9)$ \\
\hline Death of spouse & $6(5)$ \\
\hline Business failure & $5(4)$ \\
\hline Marital separation/divorce & $2(2)$ \\
\hline
\end{tabular}

"STEMI = ST Elevation Myocardial Infarction, "NSTEMI = Non-ST Elevation Myocardial Infarction, "*"MACE $=$ Major Adverse Cardiac Events. 
TABLE II: Demographic and clinical characteristics of depression during hospitalisation.

\begin{tabular}{|c|c|c|c|c|}
\hline Variable & $\begin{array}{c}\text { Major and Minor } \\
\text { Depressive symptoms } \\
n=57(49 \%)\end{array}$ & $\begin{array}{c}\text { No Depressive } \\
\text { symptoms } \\
n=60(51 \%)\end{array}$ & OR $(95 \% \mathrm{Cl})$ & $\mathrm{P}$-value \\
\hline \multicolumn{5}{|l|}{ Demographic Factors } \\
\hline Age (years), mean (SD) & $58.07 \pm 9.86$ & $58.25 \pm 12.29$ & $1.0(0.97-1.03)$ & 0.93 \\
\hline Female & $24(42)$ & II (I8) & \multirow{2}{*}{$3.24(1.40-7.50)$} & \multirow{2}{*}{$<0.01$} \\
\hline Male & $33(58)$ & $49(82)$ & & \\
\hline \multicolumn{5}{|l|}{ Clinical Factors } \\
\hline STEMI & $37(65)$ & $37(62)$ & $1.15(0.51-2.62)$ & 0.72 \\
\hline Ejection Fraction (mean $\pm \mathrm{SD}$ ) & $50.88 \pm 9.32$ & $54.53 \pm 8.41$ & $0.95(0.91-1.0)$ & 0.04 \\
\hline MACE & $13(23)$ & $2(3)$ & $8.57(1.84-39.94)$ & $<0.01$ \\
\hline \multicolumn{5}{|l|}{ Risk Factors } \\
\hline Visceral obesity & $39(7 \mathrm{I})$ & $36(69)$ & $1.08(0.47-2.48)$ & 0.85 \\
\hline Dyslipidaemia & $46(81)$ & $37(62)$ & $2.6(1.12-6.01)$ & 0.02 \\
\hline Diabetes Mellitus & $37(65)$ & $32(53)$ & $1.62(0.77-3.4 I)$ & 0.20 \\
\hline Hypertension & $37(65)$ & $32(53)$ & $1.62(0.77-3.41)$ & 0.20 \\
\hline Previous MI & || (19) & $17(28)$ & $0.6(0.25-1.44)$ & 0.25 \\
\hline Unemployed & $4 \mid(72)$ & $36(60)$ & I.7I (0.79-3.7I) & 0.17 \\
\hline Marital status, married & $38(67)$ & $46(77)$ & \multirow{2}{*}{$0.61(0.25-1.48)$} & \multirow{2}{*}{0.23} \\
\hline Marital status, not married & $19(33)$ & $14(23)$ & & \\
\hline High school education (secondary \& tertiary) & $48(84)$ & $54(90)$ & $0.59(0.2-1.79)$ & 0.35 \\
\hline \multicolumn{5}{|l|}{ Psychiatric factors } \\
\hline Previously diagnosed depression & $5(9)$ & $0(0)$ & $8.07(1.19-54.95)$ & 0.02 \\
\hline Family history of depression & $10(18)$ & $3(5)$ & $4.04(1.05-15.54)$ & 0.04 \\
\hline Family history of other mental illness & $5(9)$ & $0(0)$ & $\mathrm{CBC}$ & 0.03 \\
\hline Other psychiatric disorder & I (2) & $0(0)$ & $\mathrm{CBC}$ & 0.49 \\
\hline \multicolumn{5}{|l|}{ Behavioural factors } \\
\hline Alcohol use & $20(35)$ & $27(45)$ & $0.66(0.31-1.39)$ & 0.27 \\
\hline Smoker & $38(68)$ & $46(77)$ & $0.61(0.27-1.37)$ & 0.23 \\
\hline Medication non-adherence ( $\leq 75 \%)$ & $35(61)$ & $19(32)$ & $1.53(1.07-2.19)$ & $<0.01$ \\
\hline Physically Active & $14(25)$ & $29(48)$ & \multirow{2}{*}{$2.39(1.14-5.01)$} & \multirow{2}{*}{$<0.01$} \\
\hline Physically Not active & $43(75)$ & $31(52)$ & & \\
\hline \multicolumn{5}{|l|}{ Psycho-social factors } \\
\hline Level of stress, high & $44(77)$ & $18(30)$ & $7.9(3.45-18.1)$ & $<0.01$ \\
\hline Subjective stress rating & & & & \\
\hline Never & $0(0)$ & $6(10)$ & \multirow{4}{*}{$5.63(2.63-12.02)$} & \multirow{4}{*}{$<0.01$} \\
\hline Some periods & $24(42)$ & $45(75)$ & & \\
\hline Several periods & $25(44)$ & $8(13)$ & & \\
\hline Permanent stress & $8(14)$ & I (2) & & \\
\hline \multicolumn{5}{|l|}{ Financial stress } \\
\hline Yes & $29(5 \mathrm{I})$ & $13(22)$ & \multirow{2}{*}{$2.64(1.44-4.84)$} & \multirow{2}{*}{$<0.01$} \\
\hline No & $28(49)$ & $47(78)$ & & \\
\hline Major life events in preceding year & $46(81)$ & $29(48)$ & $4.47(1.95-10.25)$ & $<0.01$ \\
\hline 4-PSS score & $6(5)$ & & & \\
\hline Low & $10(18)$ & $53(88)$ & \multirow{2}{*}{$24.73(8.14-75.12)^{* * *}$} & \multirow{3}{*}{$<0.01$} \\
\hline Medium & $28(49)$ & $6(10)$ & & \\
\hline High & $19(33)$ & I (2) & $100.7(12.07-840.1)^{* * s}$ & \\
\hline Locus of control & $75(64)$ & & & \\
\hline Internal & $26(46)$ & $54(90)$ & \multirow{2}{*}{$10.73(3.98-28.92)$} & \multirow{2}{*}{$<0.01$} \\
\hline External & $31(54)$ & $6(10)$ & & \\
\hline
\end{tabular}

$O R=$ Odds Ration, $\mathrm{Cl}=$ Confidence Interval, $M A C E=$ Major Adverse Cardiovascular Event, $C B C=$ Cannot be calculated.

"I 0 subjects with missing waist circumference, " Medium vs. Low, ${ }^{* *}$ High vs. Low. 
Figure I shows the comparison between the prevalence of depressive symptoms in patients during hospitalistion and at I-month follow-up. In hospital, 60 (51\%) of the study subjects with $\mathrm{MI}$ did not suffer from any depressive symptoms, 27 (23\%) had minor symptoms and 30 (26\%) major depressive symptoms. At follow-up a greater number of patients ( $n=33$ $29 \%$ ) experienced minor depressive symptoms, while, in contrast, fewer patients were classified with major depression $(n=16 ; 14 \%)$.

Seven factors labelled sleep, anhedonia, uncertainty, mood, cognition, hopelessness, and inactivity were extracted from the CDS. These factors, together with their respective factor loadings and internal consistency estimates, are presented in Table III. Factor loadings ranged from 0.24 - 0.87. All factors demonstrated acceptible internal consistencies (Cronbachs $\alpha$ $>0.70$ ) ranging from 0.70 (anhedonia) - 0.90 (sleep).

\section{DISCUSSION}

In this single-centre prospective study, we examined the association of depressive symptoms and contributing psychosocial factors with $\mathrm{Ml}$ in 117 patients. Patients were characterised by the presence of multiple conventional risk factors for MI.

International studies have found that depression is 3 times more common in patients post acute $\mathrm{MI}$ when compared to the general population, ${ }^{(1,16)}$ with at least $45 \%$ of individuals

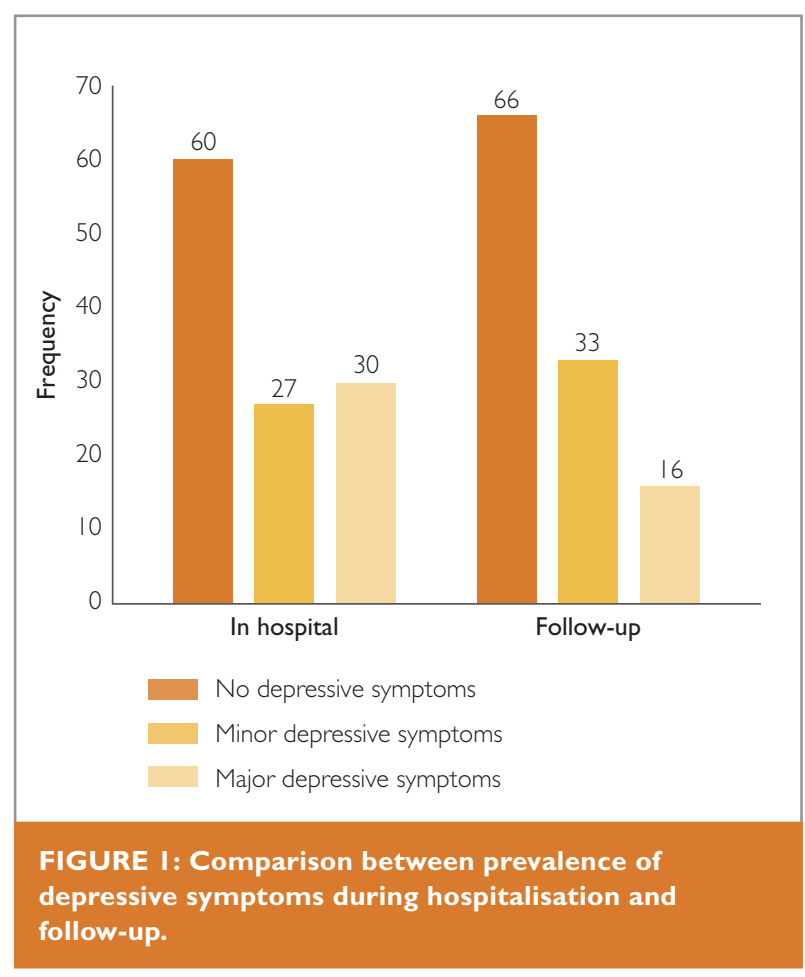

experiencing depressive symptoms. ${ }^{(17,18)}$ The presence of depressive symptoms in $49 \%$ of our patients with $\mathrm{Ml}$ compares favourably with these reports. It has been shown that depressive symptoms are associated not only with new onset cardiovascular disease, but also with recurrent events and poor outcomes in those with established disease, and supports the need to screen for depressive symptoms in our patients with MI. Several potential mechanisms have been proposed supporting depression as a risk factor for cardiovascular disease, although their relative contribution requires further elucidation. (I) These mechanisms include: hypothalamic-pituitaryadrenal axis dysfunction, inflammatory and prothrombotic changes, dietary factors, reduced heart rate variability and lifestyle factors such as smoking and physical inactivity.

Numerous previous data have shown that depressive symptoms increase all cause mortality as well as cardiovascular morbidity and mortality. ${ }^{(19-21)}$ Depressive symptoms also increase the risk of sudden cardiac death (SCD), particularly in older patients similar to other common risk variables for coronary heart disease. ${ }^{(22)}$ Altered cardiovascular regulation is one of the potential mechanisms explaining the association between depression and SCD. Furthermore, it has been noted that individuals with the highest depression scores have a significantly greater risk of developing MACE compared to those with the lowest scores. ${ }^{(19)}$ Although the duration of our study follow-up was relatively short, 13\% of patients experienced one or more MACE.

A significantly greater number of events was found in patients with depressive symptoms compared to those without $(p<0.0 \mathrm{l})$, with the 2 reported deaths occurring in subjects with depressive symptoms.

Patients with MI who experienced depressive symptoms were significantly more likely to present with a history of previous depression $(p<0.01)$ and a family history of depression $(p=0.04)$ or other mental illness $(p=0.03)$. These results suggest that depression is a chronic and recurrent disease with approximately $40 \%$ - $60 \%$ of people reporting at least one previous episode of depression, with successive episodes increasing the likelihood of recurrence. ${ }^{(23)}$ In these patients it has been demonstrated that lower levels of stress are equally capable of causing depressive symptoms, as suggested by the kindling or stress sensitisation theory. ${ }^{(24)}$ It is postulated that both cardiovascular disease and depression have substantial genetic heritability. ${ }^{(25)}$ An individual has a 2.8 - 10 times greater probability of developing depression if a first degree relative has depression. In addition, it is hypothesised that patients with depression and cardiovascular disease may represent a distinct 
TABLE III: Factors extracted from the CDS by Principal Components Analysis with Varimax rotation ( $\mathrm{n}=\mathrm{I}$ I 7 ).

\begin{tabular}{|c|c|c|c|c|}
\hline Factors & Item & Description & $\begin{array}{l}\text { Cronbach } \\
\text { alpha }\end{array}$ & $\begin{array}{l}\text { Factor } \\
\text { loading" }\end{array}$ \\
\hline \multirow{2}{*}{ Sleep } & 7 & My sleep is restless and disturbed & \multirow{2}{*}{0.90} & 0.87 \\
\hline & 9 & I wake up in the early hours of the morning and cannot get back to sleep & & 0.87 \\
\hline \multirow{3}{*}{ Anhedonia } & 4 & I get pleasure from life at present & \multirow{3}{*}{0.70} & 0.66 \\
\hline & 12 & I am in good spirits & & 0.68 \\
\hline & 19 & I gain just as much pleasure from my leisure activities as I used to & & 0.54 \\
\hline \multirow{6}{*}{ Uncertainty } & 5 & I am concerned about the uncertainty of my health & \multirow{6}{*}{0.75} & 0.48 \\
\hline & 6 & I may not recover completely & & 0.6 \\
\hline & 8 & I am not the person I used to be & & 0.56 \\
\hline & 13 & The possibility of sudden death worries me & & 0.48 \\
\hline & 17 & My problems are not yet over & & 0.69 \\
\hline & 18 & Things which I regret in life are bothering me & & 0.64 \\
\hline \multirow{5}{*}{ Mood } & 21 & I become tearful more easily than before & \multirow{5}{*}{0.78} & 0.54 \\
\hline & 22 & I seem to get more easily irritated by others than before & & 0.88 \\
\hline & 24 & I lose my temper more easily nowadays & & 0.79 \\
\hline & 25 & I feel frustrated & & 0.71 \\
\hline & 26 & I am concerned about my capacity for sexual activity & & 0.24 \\
\hline \multirow{4}{*}{ Cognition } & 2 & My concentration is as good as it ever was & \multirow{4}{*}{0.77} & 0.69 \\
\hline & 15 & My mind is as fast and alert as always & & 0.68 \\
\hline & 20 & My memory is as good as it always was & & 0.76 \\
\hline & 23 & I feel independent and in control of my life & & 0.5 \\
\hline \multirow{3}{*}{ Hopelessness } & 10 & I feel like I am living on borrowed time & \multirow{3}{*}{0.70} & 0.67 \\
\hline & 11 & Dying is the best solution for me & & 0.51 \\
\hline & 14 & There is only misery in the future for me & & 0.7 \\
\hline \multirow{3}{*}{ Inactivity } & 1 & I have dropped many of my interests and activities & \multirow{3}{*}{0.76} & 0.64 \\
\hline & 3 & I cannot be bothered doing anything much & & 0.72 \\
\hline & 16 & I hardly get anything done & & 0.68 \\
\hline
\end{tabular}

"Factor analysis using varimax rotation.

group with similar genetic burden, and that identifying this specific genomic vulnerability, could prevent the development of both diseases.

It is important to note that in hospital, $49 \%$ of patients with MI suffered from depressive symptoms, $23 \%$ had minor symptoms and $26 \%$ major depressive symptoms. At follow-up, $42 \%$ still experienced depressive symptoms with a greater number of patients having minor depressive symptoms (29\%), while, in contrast, fewer patients had major depressive symptoms (14\%). This change in pattern of symptom severity may be a transient adjustment reaction to the acute myocardial event. It is worth noting that the overall prevalence of depressive smptoms during admission and at follow-up did not significantly change, suggesting that a large number of our patients suffered from undiagnosed depressive symptoms.

Patients who present with depressive symptoms are less likely to adhere to their treatment regimen and lifestyle recommendations such as diet and exercise.(2) Similarly, in our study, patients with depressive symptoms reported lower levels of physical activity $(p<0.0 \mathrm{I})$ and poor adherence to prescribed medication $(p<0.0 I)$. Regular physical activity has been shown to improve the quality of life in people with depression ${ }^{(26)}$ and 
could serve as an important cost effective intervention in countries like South Africa which has limited resources.

A significant finding in our study was the gender differences in the prevalence of depressive symptoms. Although our study cohort consisted of more males, a greater number of females were at risk of developing depressive symptoms $(p<0.0 \mathrm{l})$. These findings concur with previous studies. ${ }^{(27)}$ It should be noted that gender embraces much more than the biological and genetic differences between men and women and is a multifaceted construct that includes psychological and social differences. In patients with MI, the higher prevalence of depressive symptoms in females may be explained by several biopsychosocial factors including: physiological changes related to menopause, lower functional capacity, as well as stressors related to social gender roles, for which women are more vulnerable than men.(27,28)

These stressors include: role conflict, role overload, lack of power, sexual abuse, and lower socioeconomic status. In addition, associated psychological traits such as emotion-focused coping styles and lower self-esteem play a role. However, conflicting data still exist in the literature, with some studies showing a poorer clinical oucome and higher mortality rates in women post Ml, while others have found that in older men but not women, symptoms of depression were linked to an increased risk of cardiovascular mortality and MACE.(29)

This highlights the importance of screening for depressive symptoms in patients with $\mathrm{Ml}$, which may improve clinical outcomes and minimise gender bias in the management of coronary artery disease patients.

Although chronic stress carries an attributable risk for cardiovascular disease ${ }^{(30,31)}$ that is on par with other recognised risk factors, such as smoking, dyslipidaemia, hypertension and diabetes, ${ }^{(7,32)}$ it is difficult to measure and little is known regarding the mechanisms that translate stress into cardiovascular disease events. Similar to the INTERHEART study, ${ }^{(7)}$ we observed that patients with depressive symptoms were significantly more likely to present with higher levels of subjective stress, greater financial stress, more major life events and scored higher on the objective 4-PSS scale. More recently, Tawakol, et al. showed for the first time that resting metabolic activity within the amygdalar of human beings is significantly associated with the risk of developing cardiovascular disease independently of established cardiovascular risk factors. ${ }^{(33)}$ Amygdalar activity and cardiovascular disease events were substantially mediated by arterial inflammation which, in turn, was substantially mediated by up-regualted bone marrow activity. These findings provide unique insights into the mechanism through which emotional stress can lead to cardiovascular disease in humans. This raises the possibility that alleviation of psychosocial stress could produce benefits that extend beyond an improved sense of psychological well-being by improving the atherosclerotic milieu.

\section{LIMITATIONS}

Several potential limitations merit consideration. Firstly, because of the relatively small sample size, the lack of a comparator, control group and the short duration of follow-up, results for smaller groups should be interpreted with caution. Secondly, this was a single centre study of a predominantly Asian Indian population and selection bias might exist.

Thirdly, depression was not diagnosed clinically using Diagnostic and Statistical Manual 5 Criteria. ${ }^{(34)}$ Although the current study has shown that the CDS is characterised by adequate psychometric properties and can detect a range of depressive symptomatology, future research should also examine the CDS with other screening measures for depressive disorders and anxiety such as the Hospital Anxiety and Depressive Scale (HADS). Finally, none of our patients were on anti-depressant medication at the time of study entry or during study follow-up. Therefore, we are unable to comment on the benefits of such therapy, particularly the use of selective serotonin re-uptake inhibitor drugs, which may improve depression in cardiac patients.

\section{CONCLUSION}

Our study shows that depressive symptoms are a common finding in a South African population presenting with MI, with a greater number of females experencing depressive symptoms compared to their male counterparts. Patients with depressive symptoms had significantly higher rates of MACE, previous history and family history of depression, greater stress levels and had experienced major life events. These findings support the notion that patients with $\mathrm{Ml}$ should be screened for depressive symptoms and psychosocial factors, because it may serve as an important arena for research and therapeutic intervention.

\section{ACKNOWLEDGEMENTS}

We thank Ms S. Ramdas for the typing of this manuscript.

\section{Conflict of interest: none declared.}


I. Lichtman $J \mathrm{H}$, Bigger JT, Blumenthal JA, et al. Depression and coronary heart disease. Circulation 2008; I 8:1768-75

2. Whooley MA, de Jonge P, Vittinghoff E, et al. Depressive symptoms, health behaviours, and risk of cardiovascular events in patients with coronary heart disease. JAMA 2008;300:2379-88.

3. McManus D, Pipkin SS, Whooley MA. Screening for depression in patients with coronary heart disease (Data from the Heart and Soul Study). AM J Cardiol. 2005;96:1076-81.

4. Bush DE, Ziegelstein RC, Patel UV, et al. Post-myocardial infarction depression. Evid Rep Technol Assess (Summ) 2005; I 23:1-8.

5. Behar S, Halabi M, Reicher-Reiss $H$, et al. Circadian variation and possible external triggers of onset of myocardial infarction. SPRINT Study Group. Am J Med. 1993;94:395-400.

6. Mittleman MA, Maclure M, Sherwood JB, et al. Triggering of acute myocardial infarction onset by episodes of anger. Determinants of myocardia infarction onset study investigators. Circ 1995;92:1720-5.

7. Rosengren A, Hawken S, Ounpuu S, et al. Association of psychosocial risk factors with risk of acute myocardial infarction in II I 19 cases and 13648 controls from 52 countries (The INTERHEART Study) Case-Control Study. Lancet 2004;364:953-62.

8. Leor J, Poole WK, Kloner RA. Sudden cardiac death triggered by an earthquake. N Engl J Med 1996;334:4 I3-9.

9. Meisel SR, Kutz I, Dayan KI, et al. Effect of Iraqi missile war on incidence of acute myocardial infarction and sudden death in Israeli civilians. Lancet 1991;338:660-661.

10. Ranjith N, Pegoraro RJ, Zaahl MG. Risk factors associated with acute coronary syndromes in South African Asian Indian participants (The AIR Study). J Clinc Experiment Cardiol (online) 20I I (cited 20 I 4 July); 2(I0): I 63 DOI: I0.4172/2155-9880.1000163.

1।. The Joint European Society of Cardiology/American College of Cardiology Committee. Redefinition of myocardial infarction. I Am Coll Cardio 2000;36:959-69.

12. Hare DL, Davis CR. Cardiac Depression Scale: Validation of a new depression scale for cardiac participants. J Psychosom Res. 1996;40:379-86.

13. Chavez CA, Ski CF, Thompson DR. Psychometric properties of the Cardiac Depression Scale: A systematic review. Heart Lung Circ 2014;23:6 10-8.

14. Shi WY, Stewart AG, Hare DL. Major depression in cardiac patients is accurately assessed using the cardiac depression scale. Psychother Psychosom 2010;79:391-92.

15. Arnold SV, Smolderen KG, Buchanan DM, et al. Perceived stress in myocardial infarction: Long-term mortality and health status outcomes. J Am Coll Cardiol 2012;60:1756-3.

16. Thombs BD, Bass EB, Ford DE, et al. Prevalence of depression in survivors of acute myocardial infarction. J Gen Intern Med 2006;21:30-8.

17. Huffman JC, Celano CM, Beach SR, et al. Depression and cardiac disease: Epidemiology, mechanisms, and diagnosis. Epub 07 Apr 2013 Cardiovasc Psychiatry Neurol.

18. Celano CM, Huffman JC. Depression and cardiac disease: A Review. Cardiology in review. 2011;19:130-42.

19. Pratt LA, Ford DE, Crum RM, et al. Depression, psychotropic medication, and risk of myocardial infarction: Prospective data from the Baltimore ECA follow-up. Circ 1996;94:3123-9.

20. Barefoot JC, Schroll M. Symptoms of depression, acute myocardial infarction, and total mortality in a community sample. Circ 1996;93:1976-80.

21. Pulska T, Pahkala K, Laippala P, et al. Follow up study of longstanding depression as predictor of mortality in elderly people living in the community. BMJ 1999;318:432-3.

22. Luukinen $H$, Laippala $P$, Huikuri $H V$. Depressive symptoms and the risk of sudden cardiac death among the elderly. Eur Heart J 2003;24:2021-6.

23. Monroe SM, Slavich GM, Gotlib $\Vdash$. Life stress and family history for depression: The moderating role of past depressive episodes. J Psych Res 2014;49:90-5.

24. Monroe SM, Harkness KL. Life Stress, the "Kindling" Hypothesis, and the recurrence of depression: Considerations from a life stress perspective. Psychological review 2005; I 12;2:417-45.
25. Mulle JG, Vaccarino V. Cardiovascular disease, psychosocial factors, and genetics: The case of depression. Prog Cardiovas Dis 2013;55:557-62.

26. Schuch FB, Vancampfort D, Rosenbaum $S$, et al. Exercise improves physical and psychological quality of life in people with depression: A meta-analysis including the evaluation of control group response. Psych Res 2016; 241:47-54.

27. Shanmugasegaram S, Russell KL, Kovacs AH, et al. Gender and sex differences in prevalence of major depression in coronary artery disease patients: A meta-analysis. Maturitas 2012;73:305-31 I.

28. Möller-Leimkühler AM. Gender differences in cardiovascular disease and comorbid depression. Dialogues in Clin Neurosci 2007;9:7-83.

29. Penninx BW, Guralnik JM, Mendes de Leon CF, et al. Cardiovascular events and mortality in newly and chronically depressed persons $>70$ years of age. Am J Cardiol 1998;8:988-94.

30. Batty GD, Russ TC, Stamatakis E, et al. Psychological distress and risk of peripheral vascular disease, abdominal aortic aneurysm, and heart failure: Pooling of sixteen cohort studies. Atherosc 20|4;236:385-8.

31. Nabi H, Kivimäki M, Batty GD, et al. Increased risk of coronary heart disease among individuals reporting adverse impact of stress on their health: The Whitehall II prospective cohort study. Eur Heart J 2013;34:2697-2705.

32. Scandinavian Simvastatin Survival Study Group. Randomised trial of cholesterol lowering in 4444 patients with coronary heart disease: The Scandinavian Simvastatin Survival Study (4S). Lancet 1994;344:1 383-9.

33. Tawakol A, Ishai A, Takx RA, et al. Relation between resting amygdalar activity and cardiovascular events: A longitudinal and cohort study. Lancet 2017;389:834-45.

34. American Psychiatric Association. Diagnostic and statistical manual of mental disorders American Psychiatric Publishers; 2013 